\title{
A large hadrosaurid dinosaur from Presa San Antonio, Cerro del Pueblo Formation, Coahuila, Mexico
}

Rogelio Antonio Reyna-Hernández, Héctor E. Rivera-Sylva, Luis E. Silva-Martínez, and José Rubén Guzman-Gutiérrez

Acta Palaeontologica Polonica 66 (3), 2021: s101-s110 doi:https://doi.org/10.4202/app.00831.2020

New hadrosaurid postcranial material is reported, collected near Presa San Antonio, Parras de la Fuente municipality, Coahuila, Mexico, in a sedimentary sequence belonging to the upper Campanian of the Cerro del Pueblo Formation, in the Parras Basin. The skeletal remains include partial elements from the pelvic girdle (left ilium, right pubis, ischium, and incomplete sacrum), a distal end of a left femur, almost complete right and left tibiae, right metatarsals II and IV, cervical and caudal vertebrae. Also, partially complete forelimb elements are present, which are still under preparation. The pubis shows characters of the Lambeosaurinae morphotypes, but the lack of cranial elements does not allow us to directly differentiate this specimen from the already described hadrosaurid taxa from the studied area, such as Velafrons coahuilensis, Latirhinus uitstlani, and Kritosaurus navajovius. This specimen, referred as Lambeosaurinae indet., adds to the fossil record of the hadrosaurids in southern Laramidia during the Campanian.

Key words: Dinosauria, Hadrosauridae, Lambeosaurinae, Cretaceous, Campanian, Mexico.

Rogelio Antonio Reyna-Hernández [rogelio.reynahr@gmail.com], Luis E.

Silva-Martínez [luis.silva.paleo@gmail.com], Laboratorio de Paleobiología, Facultad de Ciencias Biológicas, Universidad Autónoma de Nuevo León, Av. Pedro de Alba y Manuel L. Barragán s/n, Ciudad Universitaria, San Nicolás de los Garza, Nuevo León, México. C.P. 66455. Héctor E. Rivera-Sylva [hrivera@museodeldesierto.org] (corresponding author), José Rubén Guzman-Gutiérrez [paleovert@yahoo.com.mx], Departamento de Paleontología, Museo del Desierto, Carlos Abedrop Dávila 3745, Saltillo, Coahuila, México. C.P. 25022.

This is an open-access article distributed under the terms of the Creative Commons Attribution License (for details please see creativecommons.org), which permits unrestricted use, 
distribution, and reproduction in any medium, provided the original author and source are credited.

Forif Full text $(1,264.8 \mathrm{kB})$ 